\title{
When the law is silent: stigma and challenges faced by male sex workers in Japan
}

\author{
Mana Takahashi* \\ Faculty of Global Liberal Arts, Kanda University of International Studies, Japan \\ ${ }^{\star}$ Corresponding author. E-mail: takahashi-mana@kanda.kuis.ac.jp
}

\begin{abstract}
This study considers how invisibility under the law can lead to stigmatisation. It examines how legal silence affects the stigmatisation process and the identity of male sex workers in Japan. Since male sex work is currently not recognised under Japanese law, male sex workers are not subject to control, regulation, punishment or protection. However, the number of male sex workers in Japan is increasing. Many studies have noted that male sex workers may experience double stigmatisation - referring to the stigma associated with homosexuality and the stigma associated with commercial sex. Male sex workers in Japan, however, may face an additional stigma caused by the fact that the law essentially ignores their existence. This paper draws on fieldwork interviews to show how the silence of the law can exacerbate the marginalisation and disempowerment of a vulnerable social group.
\end{abstract}

Keywords: sex work; male sex workers; sexual minorities; stigma; Japanese law and society

\section{Introduction: when the law is silent, how is stigma created?}

During the interview, Tomoki said: 'It would be just unlucky if we stumble into crime or get a disease ... because we have no choice and have no way to defend ourselves.'

Tomoki concluded that the potential risks of a male sex worker depended only on luck and he seemed to accept the occupational need to place himself in situations in which he might be vulnerable. His words describe the current conditions of male sex workers in Japan. They often find themselves in a Russian-roulette situation in which they are exposed to serious risks that they must address individually and without legal protection. It makes male sex workers exceptionally vulnerable.

Who are sex workers? According to Amnesty International, a 'sex worker' can be defined as 'adults (18 years of age and above) who receive money or goods in exchange for sexual services involving sex acts between consenting adults for remuneration, with terms agreed between seller and buyer' (Amnesty International, 2016b, p. 16). The term 'sex work' has been used since the 1980s to acknowledge such work, including workers' labour rights (BuBu de la Madeleine, 2018, pp. 9-10). Sex workers often face a high level of stigma, prejudice and discrimination, which is compounded by presumptions of illegality or immorality imposed by sex-work-related laws (Amnesty International, 2016b, pp. 10-11). The situation of sex workers and domestic laws, as well as the law-enforcement practices that affect sex workers, depends on the cultural and social context of each country. The legal context can vary significantly from one country to another; for example, brothels may be strictly criminalised in one country but legal in another. However, 'the occupation' of being a sex worker is universally stigmatised and often includes job-related hazards, such as the high risk of HIV/AIDS infection. The stigma may negatively affect sex workers' work, personal life and health in all nations (Weitzer, 2018, p. 72; Benoit et al., 2017, pp. 2-4; Kaname, 2018, pp. 36-37). 
Although the social context for male sex workers is quite different from that of female sex workers, most discussions on sex work and sex workers focus on females and transgender workers. Little attention has been paid to the conditions and problems of male sex workers. According to the Global Network of Sex Work Projects (NSWP) (2014), the reason for this lack of attention on male sex workers is because male sex workers do not fit the ideal narrative of sex work proposed by research that analyses sex work as a form of violence against and exploitation of women (NSWP, 2014b, pp. 2-4). This misalignment between gender and occupation results in various outcomes, such as male sex workers not being seen as victims of sexual abuse (Oselin, 2018, pp. 241-242; Cheng et al., 2011). While most sex workers around the world are female, the number of male sex workers is not small. As of 2018, there were an estimated 42 million prostitutes worldwide and 20 per cent of them, or approximately 8 million, were male sex workers (Lehmiller, 2018; World Population Review, 2020). Most clients of male sex workers are male, but their clients can be of any gender (Minichiello et al., 2015, pp. 3-4). However, male sex workers' sexual orientations are diverse; they identify as not only gay, but also bisexual and heterosexual (Boys for Sale, 2017, directed by ITAKO, Japan, Independent; NSWP, 2014b, pp. 1-2). In this context, male sex workers may experience 'double stigmas' driven by gay sex buyers, namely the stigma associated with homosexuality and the stigma related to commercial sex (Vanwesenbeeck, 2013, p. 14; Benoit et al., 2017, pp. 3-4). Japan is no exception; the percentage of $\mathrm{MSMs}^{1}$ among male adults is approximately 4.6 per cent, and there are approximately 100 shops that target MSMs in areas around Tokyo (Community Center akta, 2017). As long as demand for the business exists, male sex workers exist and face the dangers of sexual abuse, exploitation and rape.

In the context of Japan, the focus of Japanese legislation is another possible reason for the dearth of empirical investigations into the conditions of male sex workers. Japan is categorised as a country that illegalises sex work and the hiring of sex workers in public spaces (Anti-Prostitution Act 1956 (Japan), Art. 3). In Japan, two statutes stipulate the rights and obligations of sex workers: the Anti-Prostitution Act and the Act on Control and Improvement of Amusement Business, etc. These laws were enacted by male-centric values and aimed to police female sex workers; the position of male sex workers is outside the scope of these laws and they are not subject to control, regulation and protection under Japanese law. However, recent Japanese trends suggest that many male sex workers, especially members of younger generations in Japan, have started to work 'voluntarily' rather than as forced labour due to deprivation or other social- and family-oriented factors, such as limited opportunity to find a job (Tanaka, 2015). Under the current legal system, however, they cannot enjoy labour rights.

The nature of Japanese legal regulation creates an unusual situation in which male sex workers are both stigmatised and largely invisible. The sociological theory of stigmatisation places a heavy emphasis on visibility. It is true that the classic work of Erving Goffman emphasises that visibility makes stigma a central part of 'an individual's social identity at all times during his daily round and by all persons he encounters therein will be of great importance' to the person. However, Goffman states that visible physical signs ('abominations of the body') are but one of three types of stigmatising conditions, which also include 'blemishes of individual character' and 'tribal stigma of race, nation, and religion' (Goffman, 1963, p. 4). This paper focuses on the second type of stigma, which does not necessarily depend on visibility to 'spoil' identity. Rather, such non-visible stigmas including 'homosexuality' - involve what Goffman describes as a potential for discrediting the individual, which may or may not be realised, depending on circumstances. Here, the analysis will focus on the role that law plays in contributing to the potential for stigmatisation by placing male sex workers entirely outside of the Japanese mainstream and rendering them essentially invisible, marginalised and discreditable. This form of extreme occupational marginalisation and denigration, which

\footnotetext{
${ }^{1}$ Male sex workers (MSWs) are most commonly confused with males who have sex with males (MSMs) but in a different context. Male sex work is an occupation and is MSM work, regardless of their sexual orientation. Thus, MSMs do not necessarily have a queer identity (Ishida, 2019, p. 77).
} 
is reinforced by law's silence, can be a source of shame, guilt and concealment, and is thus a form of stigmatisation resulting in part from law's silence.

Among invisible sources of stigma, Goffman explains that stigma conceals two categories of difference: one that is already known or is evident on the spot (discredited) and the other that is neither known about by those present nor immediately perceivable (discreditable). If the stigmatised individual has a discreditable identity, the person faces the issue of managing the information regarding his or her identity (Goffman, 1963, pp. 4, 41-42). In the case of male sex workers in Japan, they face the plight of dealing with a discreditable identity. Both interviewees of this paper, Tomoki and Keigo, hide their work experiences as male sex workers from their family, and Keigo has never told anyone about his working experience. This case shows that the people they encounter outside of the workplace may never learn of their job and that their stigma and discreditable condition are successfully managed.

While the law itself can make the individual visible and give protection or advantage to the person, there is also a high risk of stigmatisation. When the individual with a discreditable condition wishes to enjoy the advantage given by the law, they may have to reveal their social difference in return for legal rights. Engel and Munger explained that a dilemma that people with disabilities have to face is disclosing their need for accommodation (which can be a discreditable condition) when they claim legal protection or advantage at the workplace, and this situation may create a negative effect of stigmatising the person (Engel and Munger, 2003, pp. 9-13, 114-122).

How does the law's silence affect this process? Just as Keigo felt hopeless and could not ask for any help when he happened to drink a glass of drink with a strange drug administered by his customer, male sex workers in Japan have limited recourse. If Keigo suffers substantial damage from the drug, he has to reveal his job when he files a claim with the police or seeks a cure, and information about Keigo may reach his family. Under the silence of the law, however, Keigo may not even be able to receive appropriate remedy as a labourer and may be just discredited due to the disclosure of his information. While male sex workers in Japan are secure insofar as they can successfully manage their information in ordinary life, they possibly fall into an extremely vulnerable situation when they face certain risks. From this point of view, it can be assumed that the silence of law becomes a discreditable condition that could spoil their identity.

The key finding of this research is that invisibility under the law can in itself contribute to a stigmatising condition. Legal invisibility may drive male sex workers into a vicious cycle and result in further stigma for them due to lack of protection. This research aims to shed light on the silence of the law in Japan and how it affects the stigmatisation process and the identity of male sex workers in Japan. More generally, the principal research question it addresses is how the silence of the law can affect the stigma of marginalised and disempowered people.

This study incorporates a range of methodological approaches but primarily adopts qualitative analysis based on a socio-legal and empirical approach. As the primary data source, this research examines relevant legislation and documents, including publications by the Japanese government, proceeding records, policy statements, publications, promotion materials by community support centres for MSMs, the UN report, non-governmental organisation (NGO) reports, media releases and newspapers.

This paper also draws on two in-depth interviews with retired male sex workers (Tomoki and Keigo) regarding their life, experiences, gender identity and sexual orientation. In Rights of Inclusion: Law and Identity in the Life Stories of Americans with Disabilities (2003), Engel and Munger traced the impact of the laws in society by describing their interviewees' life stories, demonstrating how biographical narratives can reveal the presence or absence of law through the ways in which people think and behave. Similarly, this paper also considers the linkage between occupation, identity and law by considering how law becomes active or remains dormant in the lives of individuals such as Tomoki and Keigo. Like Engel and Munger's study, this research attempted to focus not on the interviewees' short period of work experience, but on their whole life, as well as social and cultural factors in society (Engel and Munger, 2003, pp. 9-13, 114-122).

To supplement the small number of in-depth interviews, I also conducted a short interview with a male sex worker and reviewed collections of interviews with male sex workers in Japan that were 
included in books, documentary films, newsletters and publications offered by the community support centres for MSMs in Japan (Boys for Sale, 2017; Nakashio, 2018; SWASH, 2018). Additionally, I interviewed staff members of community support centres in major cities in Japan (Tokyo, Osaka and Nagoya) and the executive producer of the documentary film Boys for Sale (2017), who conducted various interviews with male sex workers. This approach aims to shed light on the current situation, the challenges faced by male sex workers in Japan and the practices of support systems for MSMs, including male sex workers.

\section{Narratives of male sex workers in Japan}

Studies of law and stigma usually show either that law can alleviate the stigmatisation and marginalisation of individuals and improve their condition in society or that it can create stigma or make it worse by reaffirming their subordinate position in society. This paper, however, describes a different situation. It shows the impact on stigmatised individuals when the law remains conspicuously silent.

I begin with two narratives, both of which involve Japanese males who were former sex workers in Tokyo. As their stories indicate, although they engaged in the same occupation, their lives were quite different in many ways because of their different backgrounds and sexual orientations. One of them identifies as gay, while the other does not. Although both of them worked as male sex workers for many years, mainly through their own volition, they both faced dangerous situations, and both experienced a guilty conscience to some extent due in large part to the silence of the law.

\subsection{Story one: Tomoki}

I met Tomoki at a small music bar located in Shinjuku, which is a popular and bustling area in Tokyo. Tomoki began operating his bar in 2013, as he felt that he was too old to continue working in the sex industry once he entered his thirties. However, he still said that working at the Uri-sen bar $^{2}$ was truly his vocation.

Tomoki was born and raised in Okayama Prefecture, which is located in a rural area of Japan. He realised he was gay at a very young age. He could not tell anyone, including his family, about his sexual orientation. He stopped going to school when he was thirteen years old during the first semester of junior high school. Immediately after the compulsory schooling period, Tomoki found a job at a slaughterhouse in Okayama through a public employment agency and worked there for two years. When he was seventeen years old, he decided to move to the UK and entered a language school to study English. During his time in London, he felt free to be proud of his gay identity. He returned to Japan to renew his visa when he was nineteen years old but planned to return to London. During his stay in Japan, he temporarily stayed at his friend's home. Moreover, the visa renewal required more time than he had expected and he ran out of money. Thus, Tomoki decided to find a job and accommodation in Tokyo until the renewed visa was issued. He began to work at the 'Uri-sen bar' located in 'Shinjuku-2-Chome', which is the largest gay enclave in Asia. He found the Uri-sen bar website and contacted the shop owner. He started working there and lived in the dormitory offered by the owner to the employees. Tomoki said about his life at the dormitory: 'since I didn't go to junior high school, it was incredibly fun, and I felt that every day is a school trip.' According to Tomoki, usually, the employees at Uri-sen bar could become intimate immediately. Because they have a very deep and personal conversation from the beginning, such as 'Do you have a criminal past?', 'Have you ever used drugs?', 'Do you have debt?' and 'How much?', the living and working situation brought them even closer to one another. Many of his colleagues have diverse backgrounds and had experienced painful personal tragedies, but they never had to hide their secrets or feel inferior. Ultimately, Tomoki left the dormitory when he had enough savings to live by himself. Like

\footnotetext{
2‘Uri-sen (ウリ専)’ is a business in which male sex workers offer services to males, such as dating, drinking and sexual services. Uri-sen has both a brick-and-mortar establishment and a business without a physical location, and the targets are usually gay or bisexual males (Nakashio, 2018).
} 
Tomoki, most of the employees could be independent thanks to their job, but some of his colleagues were trapped in the business. They usually could not earn money and leave the dormitory. Tomoki mentioned that there is a huge gap among employees. Eventually, his visa application to the UK was rejected and he decided to settle in Tokyo. Tomoki worked at the Uri-sen bar for three years as a male sex worker and then worked at the 'BDSM (Bondage, Discipline, and Sadism \& Masochism) bar' for six years as a page boy. At the Uri-sen bar, he worked as a 'straight (heterosexual) man'. Although he is gay, he knows that straight males tend to be popular as sex workers, since they are considered more attractive, and customers pay more money to have such relationships. He served many customers inside and outside of the bar, and sometimes he visited and worked at the customers' apartments. During the same period, he passed the Japanese high-school equivalency examination and received a certificate when he was twenty-two years old.

While working as a sex worker, he experienced fear in response to his customers' behaviour, especially at customers' houses or other private spaces. Once, he was terrified because he saw his customer add some strange liquid to his meal. Additionally, when his customers were aggressive, Tomoki felt insecure and attempted to find and conceal all sharp-edged tools in the customers' room to avoid being attacked. However, he still says that working as a sex worker was his true vocation. According to Tomoki, his shop owner always protected employees from abnormal clients and incidents at the shop. He also used condoms because the owner always told him to use them. However, Tomoki was never educated about the risks and diseases. He knows that some of his former colleagues did not use condoms when their clients paid extra money and asked them not to use them, and usually they were too meek and poor to say no. Tomoki said:

'I was lucky because, fortunately, I had not been involved in any crimes .... Sex work is just one kind of job. The purpose of this job is just to earn money, and it would be meaningless if I can't earn money. I was proud of myself working as a male sex worker because I could make customers more alive and relaxed through my services. I was happy to work, and I didn't hide my job from anyone other than my family. Additionally, it was wonderful to have a place to live when I started to work. I wanted to continue to work as a sex worker if I could stay young forever. The Uri-sen bar was my place and shaped up my life. I could also meet many good people and learn many things in my life too.'

\subsection{Story two: Keigo}

Keigo is thirty-five years old and currently lives with his wife and four kids in the Kyusyu area, where he works at a manufacturing factory. He started working at 'Host-club'3 in Tokyo when he was eighteen years old. However, he accrued debt due to trouble with one of his customers. At approximately the same time, he also started using drugs. Keigo was desperate because he needed to earn money to pay his debt. One of his colleagues advised him that working at the 'Uri-sen' bar as a male sex worker could be a good and easy way to earn money in a short period. Keigo is a heterosexual male; thus, it was difficult for him to work at the 'Uri-sen' bar, but he had no choice as he wanted to survive. Once he started working at the 'Uri-sen' bar, it was simpler and easier than he expected and he could earn approximately USD 7,000 per month. Keigo said that 'working at a host club was complicated, and I might (unintentionally) bruise female customers. However, working at Uri-sen bar is very comfortable. I sometimes felt hurt, but I didn't worry about bruising anyone'. Keigo eliminated all his debt in four months. He was once arrested due to a violation of the Drug Enforcement Act when he worked at the Uri-sen bar. However, he returned to the shop after he was arrested and continued to work as a male sex worker for three years. During the period of working at the Uni-sen bar, Keigo was living in a dormitory for a year. According to him, it was a really dirty place but fun. Keigo said: 'since we all engaged in a unique job, I could share many experiences with my colleagues. Additionally, it was encouraging to talk with heterosexual male sex workers.'

\footnotetext{
${ }^{3 \prime}$ Host-club' is a store-type bar that provides male companions to women.
} 
At the Uri-sen bar, most customers are males, but female customers also visit. However, the shop gave the appearance that it served only males because the owner knows that shops targeting male customers are exempt from police crackdowns under the law. Therefore, Keigo always felt that 'I am working in a grey zone'. Once, a customer secretly added drugs to Keigo's drink. Keigo was terrified because he drank it without truly noticing. He worried about being arrested again because this incident occurred during his probation period. However, he could not consult with anyone or do anything. Keigo said that he simply felt hopeless and could not be helped. Fortunately, Keigo's health was not affected, and he still does not know what drug he consumed.

Keigo never told anyone that he used to work as a male sex worker and his family does not know about his working experiences. He believes that male sex workers have a strong negative image in society. Additionally, he stated that many of his colleagues contracted diseases. Keigo said that male sex workers are vulnerable because they are purchased as MSMs (males who have sex with males) or gay. Eventually, he decided to quit and return to working a daytime job.

\section{Socio-legal context of male sex workers in Japan}

This section presents the socio-legal framework of the research. It examines Japanese legislation related to sex work and sex workers to highlight the position of male sex workers under Japanese law. The current Japanese law demonstrates two things: law's silence for male sex workers and that related laws (and legislators) do not attempt to protect male sex workers as labour.

\subsection{Japanese legislation related to sex work and sex workers}

Japan has a long history of stipulating the rights and obligations of sex workers in general. The first legislation criminalising sex workers, enacted under the Meiji Constitution of Japan in 1947, Edict number 9 , prescribed penalties on managed prostitution, including coercing a person into sex, trafficking, soliciting, organising prostitution, operating brothels and profiting from the sex work of others (Imperial rescript regarding sentences for a person who subjects females to prostitution: Imperial rescript no. 9 under the Constitution of the Empire of Japan 1947 (Japan)). The edict was abolished and extensively amended by the Anti-Prostitution Act (Baisyun Boshi Hou) in 1956. Under that statute, prostitution is punishable by the law, which refers to sexual intercourse with an unspecified person in exchange for payment. Its explicit policy goal is to protect females in Japan from prostitution (Anti-Prostitution Act 1956 (Japan), Art. 1). Therefore, the target of both punishment and protection under the law is only female sex workers (Anti-Prostitution Act 1956 (Japan), Art. 1).

The other major legislation addressing sex workers is the Act on Control and Improvement of Amusement Business, etc. (Fuu-ei Hou), which was enacted in 1948 and revised in 2018. It is applied to organisers or managers of adult-entertainment businesses and sex workers in cases of being an accessory (the Act on Control and Improvement of Amusement Business, etc. 1948 (Japan), Arts 3, $24,27)$. This law regulates the broad content of the adult industry in Japan, including areas, operating hours and types of businesses, for public order and morals (the Act on Control and Improvement of Amusement Business, etc. 1948 (Japan), Art. 1).

These two statutes stipulate the rights and obligations of sex workers in Japan ${ }^{4}$ and they have two significant features that crystallise the Japanese context. First, managed or group prostitution is the major concern of legislators and individual prostitution or private business is not a target of the law (the Act on Control and Improvement of Amusement Business, etc. 1948 (Japan), Art. 2). They reflect the assumption that, in businesses with physical locations (Tenpo-style: brick-and-mortar establishments), as well as businesses without physical locations (Mutenpo-style), sex workers generally have an employment relationship with the business manager (Matsuzawa, 2018, pp. 91-93). The

\footnotetext{
${ }^{4}$ Similar to other laws, the Penal Code (1907) polices freedom of expression in the adult industry (Art. 174, Public Indecency; Art. 175, Distribution of Obscene Objects).
} 
second feature is that these Japanese statutes focus on female sex workers and heterosexual orientation. For example, Article 1 of the Anti-Prostitution Act clearly states that the purpose of the law is implementing measures for correctional guidance or protection for females who may be involved in prostitution or sexual intercourse to prevent them from any prostitution' (Anti-Prostitution Act 1956 (Japan), Art. 1, emphasis ). Also, Article 2 of the Act on Control and Improvement of Amusement Business, etc. regulates the scope of the application of the law for adult-entertainment businesses as consisting of 'services for a heterosexual relationship' (the Act on Control and Improvement of Amusement Business, etc. 1948 (Japan), Art. 2). Regarding homosexuals, Japan used to have a sodomy law called 'Keikanritsu-Jorei' that punished anal intercourse under the legislation enforced in 1872 and the revision in $1873 .^{5}$ This legislation is the only law penalising homosexual relationships in Japanese history; however, it had little to no impact on society and was abolished in 1882. Since then, homosexuals and sexual minorities have not been subjects of the law (Tanaka, 2016, pp. 197-199).

Thus, the current Japanese laws on sex work are based on 'a normal male who is a heterosexual and physically healthy' and a female as a sexual counterpart and a narrative that adult-entertainment businesses are for such healthy males (Aoyama, 2014, p. 225; NSWP, 2014b, pp. 2-3). Therefore, people who do not fit the 'ideal narratives' of sex work, such as male sex workers or other gendered minorities, tend to be marginalised as 'unhealthy' or abnormal and, under Japanese law, they are not within the ambit of the legislation.

\subsection{How do female and male sex workers differ in Japan?}

How does the position of male sex workers differ from that of female sex workers? To elucidate the position of male sex workers, this section explores the current conditions of female sex workers in Japan.

Kumada (2017) described working at the sex work industry as 'being girly (Onnanoko)'. This means that female sex workers are expected to offer 'feminised care' to heal their male customers (Kumada, 2017; Koch, 2020). The major reasons for working as a sex worker are poverty and the gendered economy of Japan. According to the Cabinet Office of Japan, the number of female employees in 2020 was approximately 30 million, while the number of males was approximately 37 million. However, the percentage of non-full-time workers that are female is 56.0 per cent, while 22.8 per cent of non-full-time workers are male (Gender Equality Bureau, 2020). This situation demonstrates that many females are working, but it is more difficult for them to find stable positions where they earn a sufficient salary. Additionally, the situation of female sex workers is very diverse and includes single mothers, disabled women, pregnant women and elderly women (Sakadume, 2016). Some shops in the sex industry offer not only the opportunity to work, but also diverse welfare services, such as nurseries and dormitories; these benefits help many women who are suffering from poverty and lead them to consider sex work as a viable employment option (Today's Close-up: No3458, 2014). Thus, the sex industry sometimes functions as a safety net for many females in Japan.

In Japan, female sex workers are visible legal subjects. Thus, female sex workers are generally working in a regulated space when they are engaged in their job. For example, if they work in a brothel, they can obtain formal authorisation under the current law. Additionally, the Anti-Prostitution Act (Anti-Prostitution Act 1956 (Japan), Chapter 4) has provided a programme for the protective care of women since 1963. Under the programme, the Japanese Ministry of Health, Labour and Welfare offers comprehensive support systems and facilities to help women become self-reliant, such as counselling centres for women and public and private shelters across Japan (Japanese Ministry of Health, Labour and Welfare, 1963). ${ }^{6}$ The targets of

\footnotetext{
${ }^{5}$ Amended provision of the Penal Code (1873), Art. 266.

${ }^{6}$ In 2020, there were forty-nine counselling centres for women and forty-eight women's protection facilities (indicating that all prefectures have at least one facility for women), and 1,348 counselling staff members work at these facilities (Kaname, 2017, p. 120).
} 
the programme are female victims of domestic violence, stalkers and human trafficking; ${ }^{7}$ and women in need of protection.

However, there are some critical challenges and discussions regarding the current legislation. First, the existing law as well as programmes for women's protection are outdated, as women's problems are diverse and the mechanisms available cannot always address all the issues associated with sex work. Recent discussions have attempted to enhance the current programme and broaden targets to include women who face difficult situations, including poverty, prostitution, domestic abuse, sexual assault and disabilities (Japanese Ministry of Health, Labour and Welfare, 2019, pp. 1-6). The second challenge is that the current legislation lacks the function of advocacy for sex workers due to the limited range of the application of law (Kumada, 2017, pp. 243-245). Finally, the perspective of whether the job becomes legal or illegal may influence female sex workers' thoughts and behaviour. Koch's interviews revealed that female workers expressed fear regarding whether they were working in a legal space (Koch, 2020, pp. 6-8).

As long as the current Japanese legislation stipulates that the Japanese government should offer special attention and protection, the sex industry cannot become a job like any other. Rather, female sex workers are regarded as 'women in need of protection' under the current law, not as labour (Kaname, 2017, pp. 118-119). Additionally, the policy of the Japanese government critically influences the situation of sex workers and may result in stigma and occupational discrimination. One example is that the Covid-19 pandemic in 2020 has had a devastating and unequal impact on sex workers in Japan. Due to the government's decision to close schools in response to the pandemic, the Ministry of Health, Labour and Welfare implemented a leave compensation programme for people taking time off of work to care for their children. However, the ministry excluded workers in the adult-entertainment industry and the sex industry from the programme (Nakagawa, 2020). The ministry explained that these industries were 'unworthy of receiving public funds'. Workers in the adult-entertainment industry, civil society and even some members of the National Diet (the national legislature of Japan) responded with sharp criticism regarding this occupational discrimination (Nakagawa, 2020). In response to this criticism, the Japanese government redefined the compensation programme to include workers in the adult-entertainment industry and the sex industry as benefit recipients (Ministry of Health, Labour and Welfare, 2020). Nonetheless, this event indicates that social stigma and occupational discrimination towards the adult-entertainment industry and the sex industry remain deeply rooted in Japanese society. As mentioned previously, diverse social problems, as well as the ways in which the sex industry functions as a safety net, are interrelated and create the current situation faced by female sex workers.

Therefore, it is doubtful whether being a visible subject of the law can eliminate the stigma of sex workers. The current Japanese law, while not overtly punitive, may negatively influence the identities of female sex workers and even create a stigmatised position for them in society.

However, what about the position of male sex workers? Male sex workers may not have to consider whether they are legalised or illegalised, since they are invisible subjects. During the pandemic, their situation was not even considered. Male sex workers are not even mentioned in conversations regarding protection or support mechanisms. Thus, there is an asymmetric situation between female and male sex workers in the context of the operation of the law.

\subsection{The position of male sex workers in Japan under the silence of the law}

How then does the silence of the law affect the position of male sex workers in Japan as distinguished from female sex workers?

\footnotetext{
${ }^{7}$ In response to ratifying the Palermo Protocol, Japan amended the Penal Code and enacted the new crime of buying and selling persons (Penal Code [Japan], Art. 226). While there are some cases in which female victims of human trafficking are forced into prostitution, the number of apprehensions is very small, and the Anti-Prostitution Act and the Act on Control and Improvement of Amusement Business, etc., but not the Penal Code, were adopted to deal with these cases (Yoneda, 2014, pp. 74-75).
} 
While the law is silent on the position of male sex workers in the law, the adult-entertainment business of male sex workers or sexual minorities thrives in Japan. The major cities in Japan have diverse bars for sexual minorities, with approximately 500 shops in Tokyo, 300 shops in Osaka and approximately 100 shops in middle-sized cities, such as Nagoya and Naha. There are approximately fifty 'Uri-sen bars' in Tokyo that offer sexual services to males by male sex workers.

The situation is simple: male sex workers and their businesses, including prostitution, soliciting and other activities, are not illegal or criminalised. Therefore, there are many advertisements for male sex workers in gay magazines and male sex workers post advertisements on social media. These activities of male sex workers are never illegal and cannot be criminalised under current Japanese law.

The situation is similar to the current global trend of decriminalisation, especially since New Zealand became the first country to decriminalise sex work with the passage of the Prostitution Reform Act in 2003 (New Zealand Parliament, 2012). ${ }^{8}$ Both the legislation and the government of New Zealand demonstrated the influence and effectiveness of the law by establishing a Prostitution Law Review Committee to conduct an independent assessment of the law's impact in 2008 (Open Society Foundation, 2012, p. 5). This assessment provides strong evidence that the law has had a marked effect in safeguarding the rights of sex workers to refuse particular clients and practices, and can improve employment conditions (New Zealand Ministry of Justice, 2008, pp. 43-49). Recently, many international organisations, NGOs and scholars have voiced support for decriminalisation and noted that the decriminalisation of sex workers is an effective way to protect their human rights (Godwin, 2012, pp. 1-2; Marshall, 2016, pp. 60-73; NSWP, 2014a, pp. 14-15; Kaname, 2017, p. 117; Amnesty International 2016a; 2016b; Human Rights Watch, 2019). According to Marshall, the decriminalisation of sex work does not lead to an increase in forced sex work and sex trafficking. On the contrary, decriminalisation can remove sex workers' fear of reporting to law enforcement and provide a comfortable work environment in which law enforcement can monitor unlawful practices (Marshall, 2016, pp. 64-65).

However, the Japanese context is different in one important respect: the reason male sex workers in Japan are not criminalised is because of the silence of the law and not because of progressive policies. The Anti-Prostitution Act has not been amended since 1956. Therefore, male sex workers in Japan remain marginalised due to the narrow scope of the law; they are neither criminalised nor protected by the law. ${ }^{9}$ The necessity for reviewing the law was discussed at the Committee on the Cabinet in 2005. However, the sexual entertainment business for homosexuals, especially for gay men, was not a subject of the law because there is a much smaller number of these shops for homosexuals compared to those for heterosexual males, and they are located in a confined area, so the influence of legislation was thought to be limited (Cabinet Office, 2005; Nakahashi, 2009). This debate was not based on factual evidence, and there was criticism of the suggestion that sexual minorities should not enjoy the rights and obligations of sex workers (Nakahashi, 2009). The current legislation for sex workers in Japan does not conform to the approaches used in many other progressive societies and sexual minorities are still ignored. This distinctive approach - permissive but deliberately refusing to acknowledge or address the activity that is permitted - is how the silence of the law has been created and sustained for male sex workers in Japan.

\section{Analysis of the stigmatisation process of male sex workers in Japan}

This section analyses the results of field research and interviews, conducted by myself and by other scholars, to draw an overall picture of the social context and conditions of male sex workers in Japan. It also aims to consider how the stigmatised identity of male sex workers arises and how law's silence influences this process.

\footnotetext{
${ }^{8}$ As of 2020 , New Zealand and New South Wales of Australia were the only jurisdictions that have decriminalised any sex work and sex workers. See 'Global Mapping of Sex Work Laws', 2020 (NSWP, 2020).

${ }^{9}$ As the case of punishing a gay bar without authorisation is a breach of the Act on Control and Improvement of Amusement Business, etc., see the Tokyo High Court Judgment on 20 February 1961.
} 


\subsection{The where and why of male sex workers in Japan}

There are various worksites for male sex workers in Japan. However, there are two major categories of businesses that focus on MSMs as target clients. One category is the so-called 'Uri-sen' in which male sex workers offer services to males, which is where Tomoki and Keigo worked. Male sex workers who work at Uri-sen are not always gay. According to the NSWP, many male sex workers identify as bisexual or heterosexual (NSWP, 2014b, pp. 1-2). Similarly to the global pattern noted by the NSWP, more than half of Uri-sen employees in Japan are heterosexual and engage in the job as a business (Nakashio, 2018; Boys for Sale, 2017). Moreover, sometimes, similarly to Tomoki, gay employees pretend to be heterosexual at the Uri-sen bar. Additionally, as the interviews indicated, male sex workers at Uri-sen bars are often offered dwelling places by the shop or the owner, and the employees sometimes work and live together.

The second type of business style is called 'new-half health'. The term 'new-half was originally used in the early 1990s in Japan (Hatano, 2018, pp. 112-114). 'New-half describes both transvestite and transgender people of diverse sexual orientations and gender identities in a broad sense, but often means transvestite, which is males dressing in drag (Nakashio, 2018). The business type of 'new-half health' is almost the same as Uri-sen, but the target clients and their sexual orientation are not only gay and homosexual, but also heterosexual.

Male sex workers work independently and find their clients through the Internet or social media. However, their situation, size and numbers are still mostly unknown. How have male sex workers come to conduct the business, regardless of their sexual orientation? Male sex workers engage in sex work for diverse reasons. However, the most common reason is the fundamental fact that being a male sex worker is an easy way to earn money and to have a place to live. A critically important underlying factor is that many young males in Japan suffer from poverty and marginalisation. Male sex workers usually receive their salary daily and do not need to wait for a payday every month. They can receive a high salary that is approximately the same as or more than the initial salary of college graduates and Keigo received a far higher salary than the average salary in Japan. ${ }^{10}$ The rental housing system in Japan is a major factor. Usually, renting a house in Japan requires a deposit and a guarantor for the contract; hence, a dwelling place is attractive to employees. Eligibility for sex work is not difficult and employees can usually work without academic qualifications. As Tomoki and Keigo mentioned, some employees have a number of problems stemming from poverty, such as debt, academic fees, gambling, criminal convictions and domestic circumstances (Boys for Sale, 2017; Shinohara, 2018, pp. 174-176). However, sex work may provide these marginalised young males with a comfortable place to stay. As per the interview responses, this place is safe for them to be open about their backgrounds, identity issues and experiences, and to insulate them from not only stigma and discrimination associated with being a male sex worker, but also elements associated with any inferiority complex.

In Japan, currently, there is another significant reason why some young men became male sex workers, namely the Great East Japan Earthquake in March 2011. After the massive earthquake and tsunami, which killed approximately 16,000 people, many young people lost their jobs in their hometowns. The documentary film Boys for Sale (2017) presented numerous interviews with male sex workers in Tokyo and clarified the fact that many male sex workers in Tokyo are from the affected area and work at Uri-sen to support their families. ${ }^{11}$

Uri-sen is a helpful place for males from the affected area to work because of the dormitory system. Thus, some young males from rural areas have no choice and decide to join a Uri-sen bar to work and live. In the film Boys for Sale, one male sex worker at Uri-sen bar said: 'If the disaster hadn't happened,

\footnotetext{
${ }^{10}$ In 2016, when the initial wage of a university graduate was approximately USD 1,980 , MSWs at Uri-sen could earn almost the same amount of money or even more (Nakashio, 2018).

${ }^{11}$ Boys for Sale (2017) is a documentary film that features candid interviews interspersed with animation detailing the awkward, sweet and sometimes horrific situations that these young sex workers experience. The Boys for Sale boldly tell stories of their life in underground Tokyo. In this film, the significant fact highlighted is that many heterosexual men work in Japan as MSWs.
} 
I'd have gone on to high school and gotten a job and lived in Iwate (the affected area). I'd still have been in Iwate, not here' (Boys for Sale, 2017).

In summary, a consideration of all these factors suggests that the 'reasons' for becoming a male sex worker reflect many of the current problems and challenges generally faced in Japanese society.

\subsection{A vicious cycle surrounding male sex workers in Japan}

Unpacking the reasons for being male sex workers actualises their vulnerable situation and potential risks. The lack of Japan's attempt to enact related legislation created the current situation of law's silence, thus it is difficult for male sex workers to avoid being exposed to serious risks from engaging in this job. Keigo felt that he worked in a grey zone; this situation may increase their stigma as male sex workers, resulting in a sense of shame or inferiority, making it difficult for them to make demands for change. How does this situation influence their life and stigmatised identity?

Legal invisibility may potentially introduce further risks. Under the current law, one issue is the lack of a safety net for male sex workers that provides reliable protection for their rights - including their labour rights. Hence, male sex workers are vulnerable to potential risks without the safeguards available to most other employees.

According to Higashi, the most vulnerable groups for HIV infection are MSMs, injection drug users (IDUs), sex workers and their clients (Higashi, 2011, pp. 1-4). However, under the Act on Control and Improvement of Amusement Business, etc., for example, the definition of sex work is limited to coitus and prostitution means vaginal intercourse. Other forms of commercial sex are legal and can occur in either a brick-and-mortar establishment or a business with no physical location without breaching the law (Act on Control and Improvement of Amusement Business, etc. 1948 (Japan), Chapter 1). Despite the risk of infection by sexually transmitted diseases (STDs), male sex workers have no labour rights or obligations for protection, and HIV and STD testing is officially voluntary and confidential. ${ }^{12}$ Therefore, male sex workers who do not insist on protection or have no access to testing facilities face a greatly heightened risk of infection. Additionally, male sex workers have limited means of accessing support and it is difficult for them to seek help if they are the victim of a crime, such as rape or illegal intercourse without consent. This situation is not only a problem in Japan, but also a global problem, with many tragedies worldwide. According to Transgender Europe (TGEU), 2,343 transgender people were murdered from 2008 to 2016, and 64 per cent of them were sex workers (Hatano, 2018, p. 115). Insofar as male sex workers are not guaranteed safe working conditions, they consistently face high risks and cannot rely on public support systems or safety nets. Thus, the current Japanese system can create a vicious cycle in which male sex workers become more vulnerable in society; it is easy for them to fall into this cycle and difficult to recover.

\subsection{Existing mechanisms for protecting male sex workers}

Given the lack of legal protections and obligations, how are male sex workers in Japan currently supported and connected in their life and work? This section explores existing community-based mechanisms in Japan. Since the importance of empowering sex workers has been noted by many organisations, including the UN, community-based approaches and outreach activities for sex workers have become key approaches for male sex workers. For the purposes of this paper, these approaches illustrate some of the benefits that arise when male sex workers are made visible - though not through formal legal action - and their needs are directly addressed.

In the Japanese context, community-based activities are mainly focused on comprehensive outreach and raising awareness of HIV/AIDS and STD prevention for MSMs. The Japanese Ministry of Health, Labour and Welfare commissioned a community-centre project, which has five hubs in Tokyo, Osaka,

\footnotetext{
${ }^{12}$ Current Japanese law also does not require health checks, such as HIV and STD testing, which is obligatory for female sex workers.
} 
Nagoya, Sendai and Okinawa, and two sub-offices across Japan (Japan Foundation for AIDS Prevention, 2017). ${ }^{13}$ Additionally, there is a voluntary board named 'MSM ALL JAPAN', which consists of nationwide NGOs and non-profit organisations (NPOs) that promote the enhancement of support systems for MSMs and cooperate with community centres (Japan Foundation for AIDS Prevention, 2017).

The idea for launching these community centres was developed by a task-force team in Japan in the 1990s that consisted of medical professionals, scholars and sexual minorities to raise awareness among MSMs because of the high risk of infection from HIV/AIDS and STDs (Ichikawa, 2005; MASH Osaka, 2020). Since then, each support centre has developed not only outreach activities, but also diverse activities to support MSMs, including male sex workers. They offer consultation services and free space to communicate, provide information and organise events based on visitors' demands and regional needs (Community Center akta, 2020; Community Center dista, 2020; Community Center rise, 2020). The age range of visitors is also broad, ranging from teenagers to people in their seventies (Community Center akta, 2017). One of the most significant functions of the community centre is its role as a one-stop spot supporting MSMs, since most visitors of the community centre are gay or bisexual MSMs. ${ }^{14}$ Each community centre has stakeholders in its region, including the Bar Association, medical agencies, governmental agencies and adult-entertainment shops and bars (Community Center akta, 2017). The community centre named 'akta' ${ }^{15}$ in Shinjuku-2-Chome of Tokyo, which is located in the town with the largest gay population in Asia, established a strong relationship with institutions for HIV/AIDS prevention, including NGOs, research institutions, medical agencies and educational institutions, and the gay community, including clubs, gay bars and adult-entertainment businesses, to create solidarity for outreach activities (Community Center akta, 2020). The centres use these networks as liaisons between visitors and necessary social and institutional support, and this function improves access to services for MSMs and male sex workers.

Offering the 'space' to encounter and develop networks among MSMs helps to ameliorate their social stigma. There is a large demand among MSMs in Japan to find role models for their life plans as a sexual minority, use consultation services and find space to openly express their identity (Goto interview, 2019). Therefore, the staff of the community centre create various publications to reach out. The community centre in Osaka called 'dista', ${ }^{16}$ which is run by the voluntary association MASH (Men And Sexual Health) Osaka, holds regular open meetings. The meetings welcome all people interested in the activities of the community centre and provide valuable opportunities for the centre to learn about and discuss regional demands and tailor their publication designs based on the preferences of MSMs and gay men (Miyata interview, 2019).

Additionally, the characteristics of the region influence the community centre's policy and priorities for its activities. The situation shows regional variation. Currently, Shinjuku-2-Chome in Tokyo attracts tourists as a popular gay town in Asia and many sexual minorities from foreign countries visit the town. Visitors to the community centre in Tokyo, therefore, can obtain information in various languages, such as in English, Chinese, Korean, Spanish and Japanese. Currently, 72 per cent of the visitors come to the centre as first-time visitors (Community Center akta, 2017, p. 17). In contrast, at the community centre in Nagoya, Aichi Prefecture, most visitors are regulars. The number of bars and shops for sexual minorities in proportion to the total population is lower in Nagoya than in Osaka and Tokyo, and the community tends to be smaller. ${ }^{17}$

Establishing these community bases may represent significant developments for the empowerment of MSMs in Japan and may enhance their access to services and support. They are particularly

\footnotetext{
${ }^{13}$ In 2020, to support community centres, a package for promoting community centres for sexual minorities was developed and sponsored by the Japanese Ministry of Health, Labour and Welfare (Japan Foundation for AIDS Prevention, 2020).

${ }^{14}$ According to a session report of 'akta', 76 per cent of visitors are gay or bisexual MSMs and 24 per cent are others (including female visitors) (Community Center akta, 2017, p. 17).

${ }^{15}$ 'Akta' derives from the letter '芥 (Akta in Japanese)' which means 'castaway' (MixOnline, 2003).

${ }^{16}$ 'Dista' is an abbreviation for 'Drop in Station' (Community Center dista, 2020).

${ }^{17}$ There are approximately eighty shops and bars for sexual minorities in Nagoya (including just five Uri-sen bars), while there are approximately 800 in Tokyo and 300 in Osaka (Community Center akta, 2013).
} 
important in light of the lack of policy and legislation for protecting male sex workers. However, a difficult challenge remains, especially in some localities. Two of the sub-offices in Ehime and Kanagawa are not supported by the Japanese Ministry of Health, Labour and Welfare but are run with a limited budget from the local government (Iwahashi et al., 2011). Therefore, their activities are not stable and are temporary. The creation of long-term and sustainable support-system mechanisms throughout Japan is critical.

Another issue involves those who could benefit from community centres. Since community-based activities and support target MSMs and mainly focus on gay males and transgender people, it is difficult to reach out to heterosexual males. As discussed, heterosexual males work as sex workers as a way to survive due to social changes, natural disasters, family problems and other current challenges in Japan. However, heterosexual male sex workers are not targets of existing community-based support and are not guaranteed access to appropriate services and help. Furthermore, it is difficult for them to become aware of and access community-centre support. In this context, the most vulnerable group may be heterosexual male sex workers. Thus, the mechanisms by which a safety net reduces risks and supports male sex workers exist but require improvement and expansion.

\section{Social stigma by the silence of the law: how invisibility, stigmatisation and the law are interconnected}

As Goffman explained, stigmatising conditions as blemishes of individual character do not always have to be visible. An invisible source of stigma can be discreditable for the individual; thus, the individual faces the issue of managing information to avoid problems in his life, as well as spoiling his identity by revealing discreditable condition. This research considered the role of law in the process of stigmatisation and how the invisibility caused by the silence of law affects the individual. To clarify the issue, this research explored the situation of male sex workers in Japan to consider how legal invisibility contributes to creating their stigma.

How does the stigma created by invisibility differ from the more visible symbols of the 'spoiled' identity discussed by theorists such as Goffman? First, invisibility contributes to unconcernedness or lack of attention towards the subjects, and it contributes to a societal perception - and a self-perception - that they have little value as human beings. Compared to female sex workers, who are characterised as people to be pitied or targets of remedy, male sex workers are essentially non-existent people. This situation jeopardises their status as employees and leads to a risk of abuse because people tend to think their invisibility makes any actions towards them acceptable. The lack of recognition of male sex workers as legal subjects and the silence of the law create a distortion of their lifestyle and introduce potential risks for which there are no proper safety nets. Consistently with Keigo's story, Aoyama also noted that laws regulating sex work divide sex workers into a dichotomy of criminals or victims, but they also create a 'grey zone' for in-between people who are not recognised and therefore go uncategorised (Aoyama, 2018, pp. 141-145). Under current Japanese law, male sex workers fall into the grey zone due to a lack of recognition. As a result of this situation, male sex workers in Japan cannot receive fair treatment in the workplace and society, and are left in an extremely vulnerable position. From this context, the fact that they 'work in the grey zone' may work as a discreditable source or a discredited source to spoil their identity. Thus, when the law is silent, Tomoki and Keigo are put at greater risk, and society is encouraged to view them as people who are not worthy of respect or protection. Male sex workers in Japan are facing multilayered stigmatised conditions, which are homosexuality (MSMs), commercial sex as their occupation and the legal invisibility attached to their occupation. These are interrelated as a condition of stigma and become an area to be managed to avoid spoiling their identity.

However, countless socio-legal studies have demonstrated that even the best-intentioned laws often fail to achieve their desired results and sometimes produce unintended negative consequences (Engel and Munger, 2003; Godwin, 2012). Additionally, as mentioned previously, to enjoy legal rights, the individual must disclose their social difference, such as their minority groups, disability and race, and this situation may lead to further feelings of inferiority or stigma. 
Male sex workers in Japan may face a similar risk if they become a visible subject of law. In the case of Japan, while being visible under the law can offer legal protection and recognition as labour, it may work as a punitive measure used to regulate and control them. This situation would make it difficult for male sex workers to control or manage their critical information, which may be discreditable. Tomoki and Keigo were able to successfully manage their information to protect themselves; however, this may not have been possible if they were visible under the law. Thus, there is scepticism regarding whether being a visible legal subject can eliminate stigma.

While being legally visible may affect the individual negatively, it is also significant that being a legal subject is essential to receive legal protections and intervention when male sex workers are the victims of violence or crime. From this point of view, it is even difficult to predict whether legal visibility can be beneficial in terms of providing legal rights and protection.

The current situation of female sex workers in Japan may help in understanding the effect of being legally visible for male sex workers. The dilemma that female sex workers are facing is similar to that of other minority groups, as they are required to reveal their occupation and personal information in return for seeking legal rights as labourers (Kaname, 2017; 2018). However, their occupation itself becomes a discreditable source for them and may lead to occupational marginalisation and denigration. Additionally, their crucial concern is whether their job and the shop where they are working become legal or illegal, which may influence their behaviour (Koch, 2020, pp. 6-8; Kumada, 2017, p. 33).

This situation is decidedly different from the dilemma of male sex workers in Japan. While the concern of female sex workers is based on the presupposition that they are labourers who work in a regulated space, male sex workers do not have the same concern, as they work in a grey zone. It is also doubtful that the stigma of male sex workers can be eliminated or be a situation similar to that of female sex workers if they become legally visible. Since Japanese society generally lacks a conversation or dialogue regarding the legal status of sexual minorities and people with occupational marginalisation, just being legally visible is not enough to eliminate the multiple layers of stigma in society.

In summary, examining the current situation of male sex workers is important for clarifying the relationship between law and visibility, and the impact of the silence of the law. While the visible condition of the stigma is discredited, visibility and invisibility under the law is a matter of being a discreditable condition for spoiling identity. What the comparison between the situation of male sex workers as invisible legal subjects and female sex workers as visible legal subjects presented is the disparity in the process of stigmatisation and their crucial concerns. Being visible under the law can contribute to providing legal rights and can protect the individual from violence and crimes. However, there are also significant risks to being visible under the law. Therefore, it is still uncertain whether becoming legally visible can be a fundamental solution for eliminating stigma and the legal position of male sex workers in Japan remains a matter in need of consideration.

\section{Conclusion}

'Seeing from inside of a bar counter, all human beings look the same, regardless of sex, identity, belief, and any background. Because everyone is living every day to the fullest.' Tomoki made this statement while working at his bar. His words provide a fitting conclusion for this study as a reminder that all human beings must be treated equally and enjoy fundamental human rights.

Due to the silence of law, male sex workers in Japan currently lack labour obligations and rights. Male sex workers must not face a situation of 'Russian roulette' with regard to the risks they face, including crime and disease, and they must be protected by the social system. From this point of view, being a legal subject is an important means to protect marginalised people, including male sex workers, in Japan from risks, violence and discrimination. On the other hand, they should also consider that they may have to accept the liability of disclosure of their social difference, which is a discreditable condition, spoiling their identity. 
As an alternative measure to being a legal subject, a soft approach, such as community-based activities, is significant and helpful for the general improvement and recognition of the conditions of male sex workers in Japan. The insights gained from the field research on the existing support centres may clarify the significance of their role as supplementary to current legislation. These voluntary systems help to protect male sex workers from not only the risk of disease and HIV/AIDS infection, but also broader potential risks, such as sexual harassment, violence, coercion and poverty. However, it is also necessary to consider the solutions for making them sustainable mechanisms as support systems throughout Japan, as well as enhancing outreach activities targeting heterosexual male sex workers.

In the case that legal reform is implemented in Japan, the process of revision may be beneficial by providing a proper acknowledgement of male sex workers. Inaugurating a legislative process that involves diverse actors in the sexual entertainment business could stimulate a dialogue about the rights of male sex workers and sexual minorities in Japan more generally. This comprehensive process may contribute to reducing the onerous stigma of male sex workers, such as Tomoki and Keigo.

The silence of the law is not always harmful and being a legal subject cannot be a fundamental solution to eliminate the stigma that this group faces. However, if the silence of the law ends, then the position of male sex workers could be changed. It is significant to understand whether, compared to being visible by the law, the silence of the law creates a critically different impact and stigma. It is also important to consider the source of the stigma of marginalised and disempowered people and determine a solution that can help them to venture out of the 'grey zone' towards acceptance in mainstream Japanese society.

Conflicts of Interest. None

Acknowledgements. I would like to acknowledge the interviewees and practitioners who kindly agreed to participate in interviews for this research project. I highly appreciate Mr Ian Thomas Ash, the documentary film director and the executive producer of Boys for Sale (2017), for inspiring me. I would also like to express my gratitude and appreciation to Professor Emeritus David Engel (SUNY Buffalo), Associate Professor Lynette Chua and Dr George Radics (National University of Singapore), whose guidance and support have been invaluable. A draft of this paper was presented at the 'Stigmatization, Identities and the Law: Asian and Comparative Perspectives' workshop on 22-25 June 2020, supported by Academic Research Fund Tier II (MOE2018-T2-1-101) and hosted online by the Centre for Asian Legal Studies at the National University of Singapore. This work was also supported by Japan Society for the Promotion of Science (JSPS) KAKENHI (Grant-in-Aid for Early-Career Scientists ), Grant Number 20K20095.

\section{References}

Amnesty International (2016a) Amnesty International Policy on State Obligations to Respect, Protect, and Fulfil the Human Rights of Sex Worker (POL 30/4062/2016). Available at https://www.amnesty.org/download/Documents/ POL3040622016ENGLISH.PDF (accessed 18 August 2020).

Amnesty International (2016b) Sex Workers at Risk: A Research Summary on Human Rights Abuses against Sex Workers. London: Amnesty International. Available at https:/www.amnestyusa.org/wp-content/uploads/2016/05/POL4040612016ENGLISH.pdf (accessed 18 August 2020).

Aoyama K (2014) Globalization and sex work: deeping risks and increasing social action. Syakaigaku-Hyoron 65, $224-238$. Aoyama K (2018) How we can prevent sexual abuse for sex workers. In SWASH (eds), Sex Work Studies. Tokyo: Nihonhyoronsha, pp. 138-159.

Benoit C et al. (2017) Prostitution stigma and its effect on the working conditions, personal lives, and health of sex workers. The Journal of Sex Research 55, 1-15.

BuBu de la Madeleine (2018) Until acquiring the terminology of 'sex work'. In SWASH (eds), Sex Work Studies. Tokyo: Nihonhyoronsha, 9-28.

Cabinet Office (2005) Bill for Partial Amendments to the Act on Control and Improvement of Amusement Business, Etc, Conference Proceeding of the National Diet. Available at https://kokkai.ndl.go.jp/\#/detail?minId=116314889X00220051027 (accessed 18 August 2020).

Cheng L, De Die L and De Kroon E (2011) Just business? The unknown world of male prostitution in the Netherlands. Humanity in Action. Available at https:/www.humanityinaction.org/knowledge_detail/just-business-the-unknownworld-of-male-prostitution-in-the-netherlands/ (accessed 18 August 2020).

Community Center akta (2013) Activity Overview. Tokyo: akta. Available at https://www.mhlw.go.jp/file/05-Shingikai10901000-Kenkoukyoku-Soumuka/0000042616.pdf (accessed 18 August 2020). 
Community Center akta (2017) Activity Report: the Year 2017. Tokyo: akta.

Community Center akta (2020) akta. Available at http://akta.jp/ (accessed 18 August 2020).

Community Center dista (2020) dista. Available at https://www.dista.osaka/ (accessed 18 August 2020).

Community Center rise (2020) rise. Available at http://aln.sakura.ne.jp/rise/ (accessed 18 August 2020).

Engel DM and Munger FW (2003) Rights of Inclusion: Law and Identity in the Life Stories of Americans with Disabilities. Chicago: University of Chicago Press.

Gender Equality Bureau, Cabinet Office, Government of Japan (2020) The White Paper on Gender Equality 2020. Available at https://www.gender.go.jp/about_danjo/whitepaper/r02/zentai/index.html (accessed 16 December 2020).

Godwin J (2012) Sex Work and the Law in Asia and the Pacific. Bangkok: UNDP. Available at https://www.undp.org/content/ dam/undp/library/hivaids/English/HIV-2012-SexWorkAndLaw.pdf (accessed 18 August 2020).

Goffman E (1963) Stigma: Notes on the Management of Spoiled Identity. New York: Simon \& Schuster.

Hatano T (2018) Transgender and sex work. In SWASH (eds), Sex Work Studies. Tokyo: Nihonhyoronsha, pp. 110-115.

Higashi Y (2011) Research on sexual behavior and consciousness of transgender SW. Research Paper on Individual Measures and Policies for HIV Prevention and an Impact of Intervention, 1-18.

Human Rights Watch (2019) Why sex work should be decriminalized: questions and answers. Available at https://www.hrw. org/news/2019/08/07/why-sex-work-should-be-decriminalized (accessed 18 August 2020).

Ichikawa S (2005) A Guideline for HIV/AIDS Infection Control for MSMs. Tokyo: Research Project for the Provision of HIV/ AIDS Prevention. Available at https://api-net.jfap.or.jp/manual/data/pdf/h18_ichikawa.pdf (accessed 18 August 2020).

Ishida H (2019) Hatten-ba (A cruising spot). In Ayabe R and Ikeda H (eds), Queer and Law. Tokyo: Nihonhyoronsha, pp. 75-110.

Iwahashi K et al. (2011) HIV/AIDS intervention programs for MSM in regional areas of Japan: how do we develop collaboration and projects with gay NGOs, local government, medical and other local organizations? Journal of AIDS Research, 115-119. Available at https://jaids.jp/pdf/2011/20111303/20111303115119.pdf (accessed 18 August 2020).

Japan Foundation for AIDS Prevention (2017) Community Centers Guide. Tokyo: Japan Foundation for AIDS Prevention.

Japan Foundation for AIDS Prevention (2020) A package of promoting community centers for sexual minorities: description of projects. Available at https://www.jfap.or.jp/business/06_doseiai.html (accessed 18 August 2020).

Kaname Y (2017) Self-reliance support for women and sex workers. Rikkyo University Annual Gender Forum 19, $117-124$.

Kaname Y (2018) Who asks a question? Literacy of the challenges of sex work. in SWASH (eds), Sex Work Studies. Tokyo: Nihonhyoronsha, pp. 30-45.

Koch G (2020) Healing Labor: Japanese Sex Work in the Gendered Economy. Stanford University Press, Kindle edition.

Kumada Y (2017) A World as Women by Sexual Play: An Ethnography of Onnanoko or Female Workers in the Japanese Sexual Industry. Tokyo: Akashishoten.

Lehmiller J (2018) Nearly one in five sex workers are men. Vice. Available at https://www.vice.com/en_us/article/evm5vw/ nearly-one-in-five-sex-workers-are-men (accessed 18 August 2020).

Marshall R (2016) Sex workers and human rights: a critical analysis of laws regarding sex work. William \& Mary Journal of Race, Gender, and Social Justice 23, 47-73.

MASH Osaka (2020) MASH Osaka (Men and Sexual Health in Osaka). Available at http://www.mash-osaka.com/ (accessed 18 August 2020).

Matsuzawa K (2018) Why laws and regulations exist and for who? In SWASH (eds), Sex Work Studies. Tokyo: Nihonhyoronsha, pp. 86-109.

Minichiello V, Scott J and Callander D (2015) A new public health context to understand male sex work. BMC Public Health 15, 1-11. Available at https://bmcpublichealth.biomedcentral.com/track/pdf/10.1186/s12889-015-1498-7 (accessed 18 August 2020).

Ministry of Health, Labour and Welfare (1963) Operating Procedure for Women's Protection. 19 March. Available at http:// www.gender.go.jp/policy/no_violence/e-vaw/kanrentsuchi/pdf/03/r_03_1202002.pdf (accessed 18 August 2020).

Ministry of Health, Labour and Welfare (2019) Midterm Report: Review Meeting on the Support System for Women in a Difficult Situation. 11 October. Available at https://www.mhlw.go.jp/content/11920000/000556504.pdf (accessed 18 August 2020).

Ministry of Health, Labour and Welfare (2020) Regarding a Leave Compensation Program for the Closure of Schools Due to the COVID-19 Pandemic. 7 April. Available at https://www.mhlw.go.jp/stf/newpage_10718.html (accessed 18 August 2020).

MixOnline (2003) The Ministry of Health, Labour, and Welfare announced to launch of gay-center for HIV/AIDS prevention. 19 August. Available at https://www.mixonline.jp/tabid55.html?artid=28785 (accessed 23 March 2021).

Nakagawa S (2020) Japan's exclusion of adult entertainment workers from public aid blasted as discrimination. The Mainichi Japan, 3 April. Available at https://mainichi.jp/english/articles/20200403/p2a/00m/0na/021000c (accessed 18 August 2020).

Nakahashi Y (2009) LGBT from the perspective of the Act on Control and Improvement of the Amusement Business, etc. Rainbow Note, 27 March. Available at http://www.junkstage.com/nakahashi/?p=18 (accessed 18 August 2020).

Nakashio C (2018) Dansho. Tokyo: Kobunsha, Kindle edition.

New Zealand Ministry of Justice, Government of New Zealand (2008) Report of the Prostitution Law Review Committee on the Operation of the Prostitution Reform Act 2003. Wellington: The New Zealand Ministry of Justice. 
New Zealand Parliament (2012) Prostitution Law Reform in New Zealand - New Zealand Parliament. Available at https:// www.parliament.nz/mi/pb/research-papers/document/00PLSocRP12051/prostitution-law-reform-in-new-zealand/ (accessed 18 August 2020).

NSWP (Global Network of Sex Work Project) (2014a) Sex Work and the Law: Understanding Legal Frameworks and the Struggle for Sex Work Law Reforms. NSWP Briefing Paper, 15 July. Available at https://www.nswp.org/sites/nswp.org/ files/Sex\%20Work\%20\%26\%20The\%20Law.pdf (accessed 18 August 2020).

NSWP (2014b) The Needs and Rights of Male Sex Workers. NSWP Briefing Paper, 21 August. Available at https://www.nswp. org/sites/nswp.org/files/Male SWs.pdf (accessed 18 August 2020).

NSWP (2020) Global Mapping of Sex Work Laws. Available at https://www.nswp.org/sex-work-laws-map (accessed 18 August 2020).

Open Society Foundation (2012) Law and Policies Affecting Sex Work. Available at https://www.opensocietyfoundations.org/ uploads/f6ae725c-4344-47b1-bc32-abec41f791c3/sex-work-laws-policies-20120713.pdf (accessed 18 August 2020).

Oselin SS (2018) Challenging stigma: identity talk among male sex workers in a recovery program. Sociological Perspectives 61, 240-256.

Sakadume S (2016) Twisted Field and Practice of Sex Industry. Tokyo: Chikumashobou.

Shinohara K (2018) Now and future of the business: from a perspective of Uri-sen owner. In SWASH (eds), Sex Work Studies. Tokyo: Nihonhyoronsha, pp. 174-180.

SWASH (eds) (2018) Sex Work Studies. Tokyo: Nihonhyoronsha.

Tanaka H (2016) Newspaper discourse of the Keikan-Zai in Meiji Era: critical discourse analysis as methodology. The Bulletin of the Graduate School of Education of Waseda University Separate (24), 197-207.

Tanaka K (2015) Heterosexual man who is pang of poverty tend to be 'Uri-sen' boys: unknown adult business for gay male. excite news, 13 July. Available at https://www.excite.co.jp/news/article/Litera_1277/ (accessed 18 August 2020).

Today's Close-up: No3458 (2014). Japan: Japan Broadcasting Corporation.

Vanwesenbeeck I (2013) Prostitution push and pull: male and female perspectives. Journal of Sex Research 50, 11-16.

Weitzer R (2018) Resistance to sex work stigma. Sexualities 21, 717-729.

World Population Review (2020) Countries Where Prostitution Is Legal 2020. Available at http://worldpopulationreview.com/ countries/countries-where-prostitution-is-legal/ (accessed 18 August 2020).

Yoneda M (2014) What has changed after Japan established a criminal offense in the conduct of buying and selling persons in 2015? Women's Studies Forum 28, 70-86.

\section{Interviews}

Goto, D (MASH Osaka). 2019. Interview by author. 17 July 2019, Japan.

Keigo (pseudonym; a former sex worker). 2020. Interview by author. 6 August 2020, Japan.

Miyata, L (MASH Osaka). 2019. Interview by author. 17 July 2019, Japan.

Tomoki (pseudonym; a former sex worker). 2020. Interview by author. 15 June 2019; 18 June 2019; 29 July 2020 , Japan.

Cite this article: Takahashi M (2021). When the law is silent: stigma and challenges faced by male sex workers in Japan. International Journal of Law in Context 17, 301-317. https://doi.org/10.1017/S1744552321000409 